\title{
The Green Aggregates for Sustainable Development in Construction Industry
}

\author{
Sundeep C Daggubati* and Nazneen
}

Final year, Bachelor of Engineering, Department of Civil Engineering, Hindustan Institute of Technology \& Science, Chennai, India

\begin{abstract}
Solid waste management is being done in several ways but there is a need for an effective and a creative way that aims to bring sustainable development in the construction industry. Existing methods of waste management and disposal like the land filling is ultimately polluting the soil and ground water. The need for manufactured aggregates is to promote the 3 R's (Reduce, Reuse \& Recycle) and to achieve a sustainable development. Manufactured aggregates may reduce environmental strain by minimizing over exploitation and indiscriminative use of natural aggregates which we get from the mining, quarrying and blasting activities. Waste is not a waste unless you waste it. This paper focuses on the synthesis of an ingenious construction material (Coarse aggregates) from the various industrial wastes which are ceramic materials, lathe waste and plastics (Low density \& Medium density polyethylene) along with slag (fly ash/ Ground Granulated Blast furnace Slag) in definite proportions. Coarse aggregate synthesised through this process have both advantages and disadvantages when compared to the natural aggregates. Various tests for aggregate which are specified in the IS 2386 does not seem applicable as these artificial aggregates undergo elastic or plastic deformation.
\end{abstract}

Keywords: Aggregates; Ceramics; Industrial waste; Lathe waste; Plastics; Quarry dust

\section{Introduction}

Over exploitation of resources is what the human being got habituated to do with the environment. Indiscriminate usage and exploitation of resources is causing environmental strain. Mining and quarrying for the natural aggregates which are prerequisites for every construction activity is depleting the natural resources and deteriorating the environment [1]. Activities like mining and quarrying are resulting in the loss of habitat, agricultural lands, forests, Biodiversity and are also resulting undesirable climatic changes. Mining activities and stone crushing units contribute to both sound and air pollution. The current years are already witnessing the scenario of fast depletion of natural resources and the construction industry that mostly depends on aggregates is also on the verge of loss due to their shortage and unavailability. Natural aggregates still remain as the most mined material in the world [2]. Environmental laws and restrictions are curbing the mining activities as far as possible. River sand mining is almost banned in India and there won't be any future contracts given by the government to private mining agencies. Recent decades have seen a marked upsurge in industrial and economic growth, contributing to an improved quality of life and well-being for citizens [3]. However, we should not lose sight of the fact that every production system creates by-products and waste products which can affect the environment. These effects may occur at any point in the product's life-cycle, whether during the initial phase of obtaining raw materials, during the transformation and production phase, during product distribution or when the end user must dispose of products which are no longer required. As a result, recent years have witnessed rising social concern about the problem of waste management in general, and industrial waste and waste from the construction industry in particular. This problem is becoming increasingly acute due to the growing quantity of industrial, construction and demolition waste generated despite the measures which have been taken in recent years.

Management of solid waste reduces or eliminates adverse impacts on the environment and human health and supports economic development and improved quality of life. A number of processes are involved in effectively man aging waste for a municipality. These include monitoring, collection, transport, processing, recycling and disposal.

\section{Material Selection and Composition}

Artificial aggregates were assumed to be formed from the combination of a binder and ingredients which are industrial wastes. The binder needs to be a pollutant which is a liquid or semi-solid or amorphous substance, industrial waste, should be non-reactive (inert) and should have the ability to hold the ingredients (solid wastes) intact with each other to form a heterogeneous mixture that can be used in casting aggregates. The following materials are chosen based on their following characteristics which they exhibit when alone or in combination: Ceramics- Breakage or deformation, which does not affect the intrinsic characteristics of the Ceramic material; Reduced $\mathrm{CO}_{2}$ emissions; Long-term mechanical strength; Stable resistance to expansion due to the presence of free lime, sulphates and aggregatealkali reactions; Durability and resistance to the action of pure and acid water; Reduced hydration heat; Impermeable; Reduced porosity and increased compactness. Slag [4,5] Excellent mechanical properties; Inertness to chemicals; Impermeable; Mouldable; Adhesion. PlasticsReduces water absorption; reduced porosity; Binding and lamination. Lathe waste- Lightweight; Supplements strength; Reinforces the mixture.

\section{Proportionating}

Manufactured aggregates constituted equal volumes of solid wastes which included ceramic pieces of size less than $12.5 \mathrm{~mm}$ and greater than $10 \mathrm{~mm}$, crushed lathe waste, amorphous waste including mostly fly ash and quarry dust. Plastic chunks which were used to hold the ingredients of at least 4 to 5 manufactured aggregates are of size $3 \mathrm{~cm} \mathrm{x}$

*Corresponding author: Sundeep C Daggubati, Final year, Bachelor of Engineering Department of Civil Engineering, Hindustan Institute of Technology \& Science, Chennai, India, Tel: 91-9962773097; E-mail: sundeepcdaggubati@gmail.com

Received July 08, 2014; Accepted October 03, 2014; Published October 10 2014

Citation: Sundeep CD, Nazneen (2014) The Green Aggregates for Sustainable Development in Construction Industry. J Civil Environ Eng 4: 158. doi:10.4172/2165784X.1000158

Copyright: (c) 2014 Sundeep CD, et al. This is an open-access article distributed under the terms of the Creative Commons Attribution License, which permits unrestricted use, distribution, and reproduction in any medium, provided the original author and source are credited. 


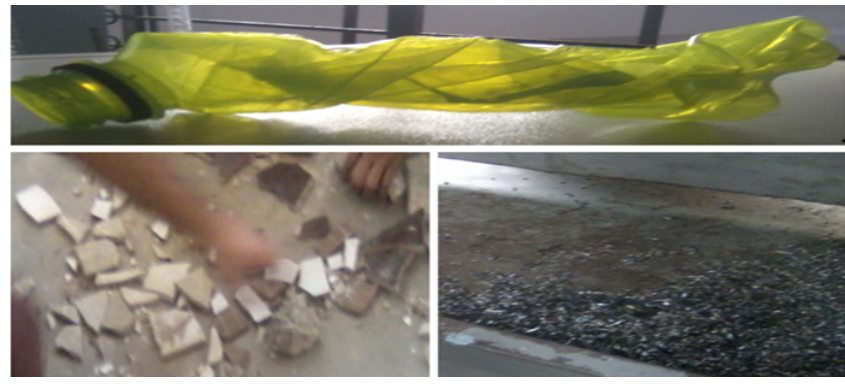

Figure 1: Constituents of manufactured aggregates-PET bottle, Ceramic waste \& Lathe waste.

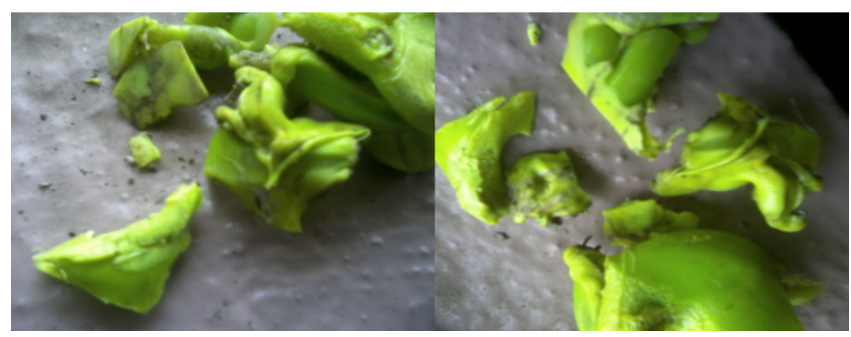

Figure 2: Manufactured aggregates using plastic as a binder.

$5 \mathrm{~cm}$ and are 2 in number. These are overlapped on each other allowing space for solid wastes to get sandwiched in between them. The number of such plastic chunks that were softened to hold the solid wastes may vary according to the type of plastic being employed in binding. Several trials were conducted to establish the required number of the quantity of plastic waste needed for the purpose of softening and binding the solid wastes (Figure 1).

\section{Molten plastic as a binder}

Medium density polyethylene products like the Polyethylene terephthalate bottles and Low density polythene carry bags were chosen and were softened to use the plastic matrix formed by them to impregnate the solid wastes. In this process, Size and shape of the aggregates is mainly dependent upon the mould or the container used in the muffle furnace. Muffle furnace should be operated between 350 to 375 degree Celsius to ensure uniform lamination and bonding of plastic with the solid wastes (ingredients). Aggregates are cooled down to the normal room temperature by taking them out just after placing them in the muffle furnace for 35 to 40 seconds.

Large scale production is also possible through a customised machinery and a plant that would allow the following operations to take place: Collection and segregation of waste, grading of waste, Plastic softening equipment, temperature controlled chamber to let the molten plastic flow, proportionating unit, moulders and a cooling tank. A large scale setup is both feasible and viable as the resources are cheaply available and are huge in terms of quantity. Procuring resources from distant and scattered areas may affect the logistics and could become a risk if not properly planned and analysed. In addition to attaining proximity to resources there are risks which are related to segregation of plastic wastes, meeting the required specifications and making the material cost effective (Figure 2 and Table 1).

\section{Disadvantages of plastic matrix as a binder}

Mass production of these aggregates seemed impossible with the available laboratory equipment as it needs a customised machinery Number of aggregates (Coarse) that can be synthesised per one medium sized PET bottle were only 3 to 5 . Controlled softening of plastic and uniform coating or lamination seemed tough to achieve using the laboratory equipment. Volatile Organic Compounds emission is another drawback.

\section{Advantages of plastic matrix as a binder}

Besides these drawbacks encountered during the synthesis of artificial aggregates with plastic as a binder, Plastic as a binder gave very light weight aggregates which are absolutely hydrophobic, highly inert and coloured aggregates. Aggregates obtained were angular and some are rounded too with grooves on them which may facilitate good interlocking. Aggregates are not brittle and they underwent plastic deformation under crushing and impact loads because of which tests specified in IS: 2386-1963 [6] seemed unsuitable.

\section{Experimental Study}

Most of the standard and important tests for aggregates like the aggregate impact, crushing and abrasion could not be conducted as these manufactured aggregates did not undergo changes which the natural aggregates will undergo when load is applied on them. To determine these important results which are mainly related to the strength characteristics of the manufactured aggregates, existing code of practice for the aggregate tests may need to be revised. Aggregates were primarily tested to assess their suitability for the application as road aggregates so their compatibility with concrete is yet to be checked and known. The following tabulation shows the results of various tests conducted on the manufactured aggregates (Table 2).

\begin{tabular}{|l|c|c|}
\hline Material & Quantity & Cost $^{*}$ \\
\hline $\begin{array}{l}\text { Ceramic Waste } \\
\text { (Tiles, crockery, bathroom fixtures ) }\end{array}$ & $15 \mathrm{~kg}-20 \mathrm{~kg}$ sack & Rs. 40/- \\
\hline Steel slag & $10 \mathrm{~kg}-15 \mathrm{~kg}$ sack & Rs. 250/- \\
\hline Quarry dust (granite) & lump some & Free \\
\hline Plastic (HDPE,PET ) & $20 \mathrm{~kg}$ & Rs. 100/- \\
\hline
\end{tabular}

*(Based on ground analysis done in Kancheepuram, TN, India)

Table 1: Cost of resources.

\begin{tabular}{|c|c|c|}
\hline Test & Value & Remarks \\
\hline Water absorption & $0.17 \%$ & Low \\
\hline Specific gravity & 2.8 & Average \\
\hline Light weight & $480 \mathrm{~g}$ less per $\mathrm{Kg}$ & Very Light weight \\
\hline $\begin{array}{l}\text { Soundness } \\
\text { Leaching with Sodium } \\
\text { sulphate } \\
\text { Leaching with magnesium } \\
\text { sulphate }\end{array}$ & $\begin{array}{l}\text { Could not be } \\
\text { determined. }\end{array}$ & $\begin{array}{l}\text { No deterioration } \\
\text { witnessed. } \\
\text { Inert. }\end{array}$ \\
\hline Aggregate crushing value & $\begin{array}{l}\text { Could not be } \\
\text { determined. }\end{array}$ & $\begin{array}{l}\text { Plastic deformation } \\
\text { occurred. Not brittle. }\end{array}$ \\
\hline Los Angeles abrasion value & $\begin{array}{l}\text { Could not be } \\
\text { determined. }\end{array}$ & Hard. \\
\hline Angularity number & 7 & Not flaky \\
\hline $\begin{array}{l}\text { Shape } \\
\text { Flakiness Index } \\
\text { Elongation Index }\end{array}$ & $\begin{array}{c}18.22 \% \\
16 \%\end{array}$ & $\begin{array}{l}\text { Angular } \\
\text { Angular }\end{array}$ \\
\hline Stripping value & $1.75 \%$ & $\begin{array}{l}\text { Good adhesion with } \\
\text { bitumen. }\end{array}$ \\
\hline Bulk density & $1087 \mathrm{Kg} / \mathrm{m}^{3}$ & Light weight/ more voids \\
\hline pH & 8.7 & Slightly alkaline \\
\hline
\end{tabular}

Table 2: Summary of experimental investigation conducted on manufactured aggregates. 


\section{Conclusion}

As far as the consumption of natural aggregates is concerned, the use of artificial and recycled aggregates as a partial replacement of natural ones has to be encouraged [7]. In this context, the recycling of huge amounts of industrial solid wastes, sludge, reservoir sediments and demolition wastes in the production of concrete and aggregates is an important issue in directing waste management towards a more sustainable development. In addition to helping protect the environment, use of such waste offers a series of advantages such as a reduction in the use of other raw materials, contributing to an economy of natural resources. Moreover, reuse also offers benefits in terms of energy, primarily when the waste is from kiln industries (the ceramics industry) where highly endothermic decomposition reactions have already taken place, thus recovering the energy previously incorporated during production [8]. Reusing plastics to manufacture various items of commercial use other than manufacturing aggregates as proposed may give rise to inferior products that ultimately end up as wastes. Hence, there is a scope for managing plastic wastes effectively through the manufacturing of aggregates. Mining and quarrying can be reduced by employing alternative materials like these. The manufactured aggregates may become substitutes to the naturally aggregates when they become scarce in the near future. Utilisation of these aggregates for non-structural applications ensures sustainable development in the construction industry.

\section{References}

1. Jayasinghe GY, Tokashiki Y (2010) Synthetic Aggregates Produced by Different Wastes as a Soil Ameliorant, a Potting Media Component and a Waste Management Option.

2. http://www.sintef.com/home/Building-and-Infrastructure/

3. Juan A, Medina C, Guerra MI, Morán JM, Aguado PJ, et al. (2010) Re-use of ceramic wastes in construction.

4. Kokot D, Cotič Z, Primorje DD, Bianco L, Nord F, et al. (2010) Application of steel slag aggregate in road construction.

5. Barišić I, Dimter S, Netinger I (2010) Possibilities of application of slag in road construction. Technical Gazette 17: 523-528.

6. Bureau of Indian Standards.

7. Priyadharshini P, Ganesh GM, Santhi AS (2011) Experimental study on Cold Bonded Fly Ash Aggregates. International Journal of Civil and Structural Engineering 2: 493-501.

8. Ferone C, Colangelo F, Messina F, Lucolano F, Liguori B, et al. (2013) Coa Combustion Wastes Reuse in Low Energy Artificial Aggregates Manufacturing Materials 6: 5000-5015. 